\title{
Sporcularda plantar fasya rüptürleri
}

\author{
Plantar fascia ruptures in athletes
}

\author{
Uğur Şaylı ${ }^{1}$, Onur Kocadal ${ }^{1}$, Neslihan Taşdelen ${ }^{2}$ \\ ${ }^{1}$ Yeditepe Üniversitesi Hastanesi, Ortopedi ve Travmatoloji Anabilim Dalı, İstanbul, Türkiye \\ ${ }^{2}$ Yeditepe Üniversitesi Hastanesi, Radyoloji Anabilim Dalı, İstanbul, Türkiye
}

\begin{abstract}
Günümüzde özellikle gençlerin ve genelde toplumun spora ilgisinin artması, sporun yaygınlaşması, ayak problemleri ile daha sık karşılaşılmasına neden olmaktadır. Bu ayak problemlerinin önemli bölümü plantar fasyanın kronik ve tekrarlayıcı travmalara maruz kalmasından kaynaklanmaktadır. Plantar fasya rüptürleri fasiitis ile kıyaslandığında nispeten nadir görülen yaralanmalar ise de, profesyonel sporcular gibi yüksek beklenti içerisinde olanlarda hızlı ve doğru tanı konması, olguların sportif aktivitelere erken dönüşü için kritik önem arz eder. Kesin tanı, ayrıntılı anamnez yanı sıra klinik ve radyolojik değerlendirme ile konur. Hastalığın cerrahi tedavi seçenekleri tanımlanmış olmakla beraber, sıklıkla tercih edilen tedavi yaklaşımı cerrahi dışı tedavilerdir. Uygun tedavi edilmeyen hastalarda kronik taban ağrısı ve azalmış sportif performans gibi problemlerle karşılaşılabilir. Özellikle sporcularla uğraşan uzmanların tanı ve tedavi algoritmalarına hakim olması gerekmektedir.
\end{abstract}

Anahtar sözcükler: plantar fasya; ayak; rüptür
Today, the increasing interest in sports, especially among young people and society in general, and due to the spread of sportive activities, foot problems are encountered more frequently. These common foot problems are mainly due to chronic and repetitive strains of plantar fascia. Even though plantar fascia ruptures are less frequent than fasciitis, they require more comprehensive clinical evaluation and management especially in sports professionals; rapid and accurate diagnosis of those with high expectations is critical for the early return to sporting activities. A thorough examination and clinical evaluation with appropriate imaging modalities lead to accurate diagnosis. Non-surgical treatment modalities are preferred more frequently than surgery, and results are mostly satisfactory. Unsuccessful treatments end with chronic symptoms, and problems such as chronic pain and reduced sport performance may be encountered. The sports injury specialists need to know about the diagnosis and several treatment modalities to manage these injuries successfully.

Key words: plantar fascia; foot; rupture
A yak, anatomik lokalizasyonu, yük taşıyıcı özelliği ve aksiyel vücut planlarından farklı konumlanması nedeniyle, tekrarlayıcı kronik travmalarla sıkça karşılaşır; özellikle de sporcularda bu tekrarlayıcı yüklenmeler ve yaralanmalar daha da sıktır. ${ }^{[1-4]}$ Plantar fasya (PF) problemlerinin toplumda \%10 civarında olduğu kabul edilir, PF rüptürleri ise daha nadirdir. ${ }^{[4-6]}$

\section{ANATOMI VE FIZYOPATOLOJi}

$\mathrm{PF}$, ayak tabanında tuber kalkanei'den başlayan ayak parmakları proksimal falankslarına yapışan kuvvetli bir bağ dokusudur. Yapı, ayağın tabanını travmalardan korur, arkları destekler ve stabilize eder, her bir yürüme siklusunda da değişik yüklenmelere maruz kalır.
Mediyal, lateral ve santral kısımlarından en belirgini santral kısmıdır, en çok yakınmalar ise mediyalde, özellikle de kalkaneus başlangıç yeri civarında olur. Yenidoğandan başlayarak ergenlik döneminin sonuna dek, Aşil tendonu ile PF'nin direkt bağlantısı vardır; erişkin dönemde ise bu bağlantı zayıflar ve hatta yok denecek kadar azalır. ${ }^{[2,5]}$

\section{ETIYOLOJi}

PF rüptürlerinin etiyolojisinde altta yatan faktör, genellikle kronik plantar fasiitistir. ${ }^{[6-8]}$ PF'nin tekrarlayan travmaya maruz kalması, PF rüptürü ile sonuçlanır. Rüptür, spontan meydana gelebileceği gibi, PF tedavisinde ağrının ve inflamasyonun azaltılması için kullanılan kortikosteroid enjeksiyonları sonrasında

- İletişim adresi: Prof. Dr. Uğur Şaylı, Yeditepe Üniversitesi Hastanesi, Ortopedi ve Travmatoloji Anabilim Dalı, İstanbul, Türkiye Tel: 0542 - 2339307 e-posta: ugursayli@gmail.com

- Geliş tarihi: 1 Ocak $2018 \quad$ Kabul tarihi: 1 Ocak 2018 


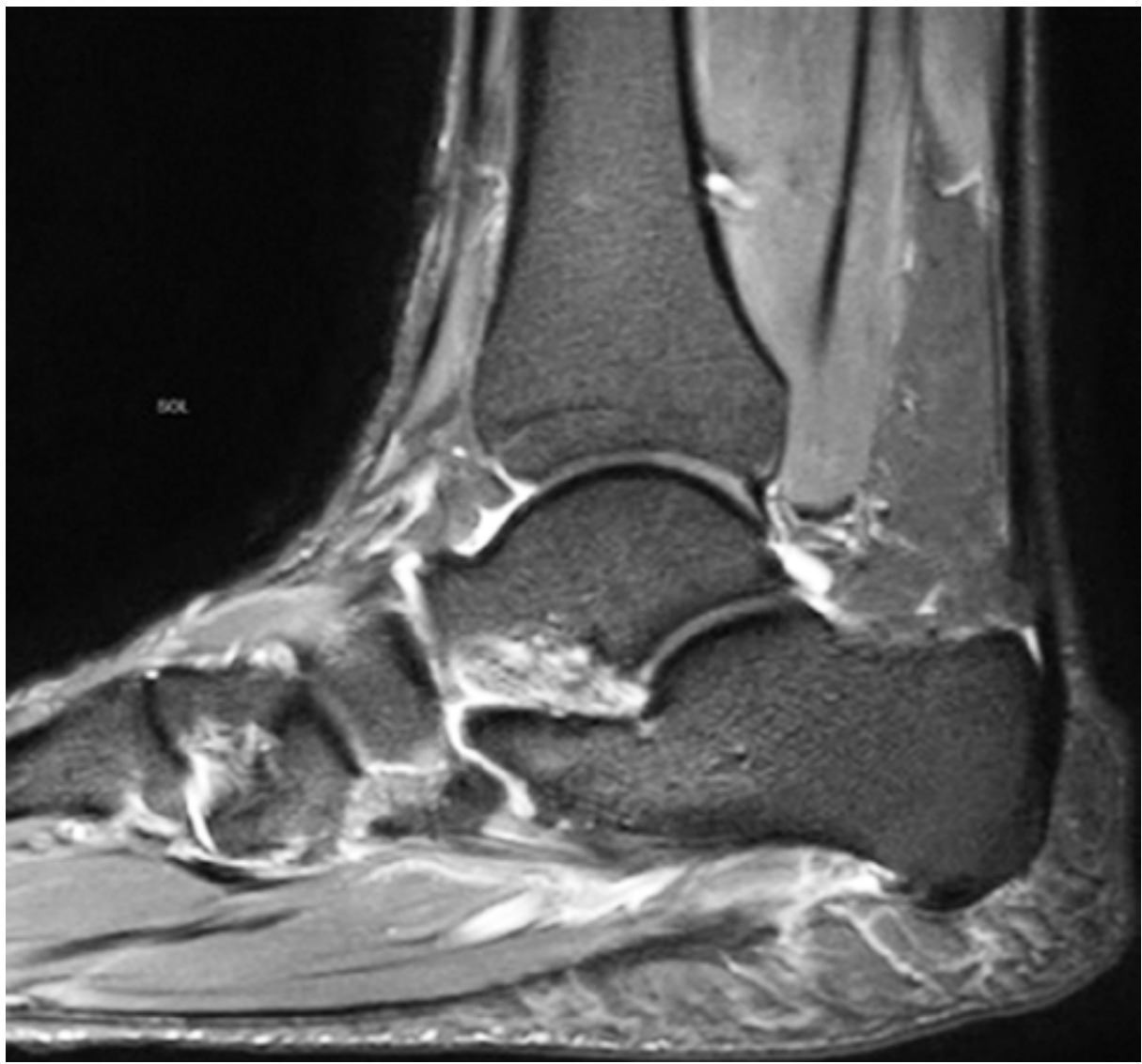

Şekil 1. Düzenli spor aktivitesi yapmayan, geçmişte plantar fasiitis tanısıyla kortikosteroid enjeksiyonu uygulaması yapılmış 50 yaşındaki hastaya ait sagittal plan manyetik rezonans (MR) görüntülemesi. Hasta, basketbol oynarken, ribaunt esnasında yere temas ettiğinde aniden oluşan ayak tabanında ağrı ve kopma hissi ile başvurmuştur. Hastanın fizik muayenesinde ayak plantar yüzde orta-mediyal bölgede yoğun hassasiyet ve ekimoz mevcuttu. Parmak ucuna kalkması ağrıyı provoke ediyordu. Hastanın MR'sinde PF'nin total rüptürü görülmektedir. Olgu, konservatif tedavi programına alınmış ve iki hafta sonra koltuk değneği desteği ile işe dönmüş; rehabilitasyon programını takiben ise 10 haftada iyileşme süreci tamamlanmıştır.

da gelişebilmektedir. ${ }^{[1,9-14]}$ Kortikosteroid enjeksiyonları PF rüptürlerinde sorumlu tutulan bir faktör olsa da, enjeksiyon sonrası rüptür oranının düşük olduğu söylenebilir. Kim ve ark., kortikosterid enjeksiyonu ile tedavi edilmiş 120 plantar fasiitis hastasını geriye dönük olarak değerlendirdikleri çalışmalarında, sadece üç olguda rüptür rapor etmişlerdir. ${ }^{[6]}$ Etiyolojide suçlanan diğer nedenler ise, Aşil tendon kontraktürü ve gergin gastrokinemius-soleus kompleksidir. ${ }^{[8]}$

PF rüptürleri nadir görülen yaralanmalar olmakla beraber, sporcularda, popülasyonun geri kalan kısmına göre daha sık izlenir. Literatürde, ilk olarak 1978 'de Leach ve ark. tarafindan altı sporcuda rapor edilmiştir. ${ }^{[12]}$ Sporcu ayağı tekrarlayan yüklenmelere daha çok maruz kalmakta olup, sporcularda PF rüptürleri de dahil olmak üzere ayak tabanında çeşitli problemlerle daha yaygın karşılaşılmaktadır. Atletlerde PF'nin zayıflaması, tekrarlayıcı zorlamalara maruz kalması ve ayak önünün hiperekstansiyonu rüptüre zemin hazırlar. ${ }^{[8,15]}$ Literatürde rapor edilen olgular, özellikle koşucular, tenis, basketbol ve voleybol oyuncuları gibi ayağın ani kontraksiyonuna maruz kalan sporculara aittir. ${ }^{[7,9]}$

\section{TANI}

Tanı, iyi bir öykü alma ve titiz bir klinik değerlendirme ile konulabilir. Hastalar sıklıkla, atletik aktivite sırasında ani gelişen bir 'pop' sesi ve yırtılma hissi tarif ederler. ${ }^{[6,7]} \mathrm{PF}$ rüptürlerinde genellikle, plantarda mediyalde aniden olan keskin ağrı, ayakta, yürürken, koşarken ve parmak ucuna kalkıldığında artan ağrı, lokal hassasiyet, ekimoz ve genel travma bulguları gözlenir. ${ }^{[16]}$ Ayak parmaklarının pasif dorsifleksiyonu ile artan ağrı izlenebilir. ${ }^{[7]}$ Sağlam ekstremite ile kıyaslandığında, birinci metatarsofalangeal eklemde artmış dorsifleksiyon mevcuttur. ${ }^{[6]}$ Bu pozisyonda PF'nin palpasyonunda bariz tonus farklılığı hissedilebilir.

Radyolojik değerlendirme; iki yönlü ayak grafileri, ultrasonografi (US) ve manyetik rezonans (MR) görüntülemeyi içerir. Olgularda ayak röntgenogramları sıklıkla normal olmakla beraber, diğer patolojilerin ekartasyonu için gereklidir. US, PF kalınlığının değerlendirilmesine olanak sağlayarak, yırtığın kısmi mi yoksa tam kat mı olduğunu ayırt etmede katkı sağlar. ${ }^{[15,16]}$ Tanı genellikle klinik olarak konsa da, şüpheli olgularda MR yararlı olabilir. MR incelemeleri sonucunda, PF rüptürlerinin sıklıkla proksimalde olduğu ortaya konmuştur (Şekil 1).[16] 


\section{TEDAVi}

Akut dönemde semptomları kontrol altına alabilmek için RICE (dinlenme, elevasyon, buz uygulama ve bandajlama), NSAii (non-steroid anti-inflamatuvar ilaçlar) ve immobilizasyon tercih edilir. Tedavide; uzunlamasına ark destekleyici ortezlerden, alçıya ve cerrahi tedavilere kadar çeşitli seçenekler mevcuttur. [17] Sedanter kişilerde konservatif yöntemler daha yoğun olarak tercih edilmektedir. Atletlerde ise tedavi yaklaşımları farklılık arz eder. Yaralanmadan sonrası erken dönemde, yüklenme olmaksızın 2-3 hafta alçı atel tedavisi uygulanır. Hastanın yakınmaları gerilediğinde, atel çıkartılarak yüklenmeye izin veren breysler ile konservatif tedaviye devam edilir. Atletlerde, özellikle uzun süre immobilizasyondan kaçınılmalıdır; immobilizasyon süresi beş haftayı geçmemelidir. Konservatif tedavinin önemli bir basamağı da fizyoterapidir. Atel tedavisine son verildiği noktada, uygun rehabilitasyon protokollerine başlanmalıdır. Atletik aktivitelere dönüş süresi, yaralanmanın ciddiyetine bağlı olmakla beraber, yaklaşık olarak 2-3 aydır. Sporcuların parmak ucunda ağrısız şekilde durabildiği noktada, koşu ve zıplama tarzı aktivitelere dönüşüne izin verilebilir. Saxena ve Fullem, PF rüptürü nedeniyle konservatif tedavi rejimi ile tedavi edilmiş 18 atletin tedavisi sonrasında, ortalama spora dönüş süresini 9,1 hafta olarak rapor etmişlerdir. ${ }^{[7]}$ Kronik durumlarda ise cerrahi tedavi alternatifleri uygulanabilmekle beraber, cerrahi sonrası sonuçlar optimal olmamaktadır.

Cerrahi tedavide, skatris dokusunun eksizyonu tercih edilebilir; her ne kadar tedavilerin karşılaştımalı sonuçlarını yansıtan çalışmalar yoksa da, Baxter ve Thigpen, elit sporcularda PF'nin komplet gevşetilmesinin iyileşme sürecini uzatacağını öne sürmüşler ama McElgun ve Cavaliere, ayrıca Leach, Jones ve Silva bu görüşü desteklememişlerdir. ${ }^{[3,12]}$

Christel ve ark., cerrahi olarak tedavi ettikleri hastaların hemen tamamının spor yaralanmasına bağlı olduğunu ve en sıklıkla cerrahi sırasında aşırı skatris eksizyonu ve fasyanın gevşetilmesi girişiminin tercih edildiğini, sonuçların ise başarılı olduğunu bildirmişlerdir. ${ }^{[18]}$ Lester ve Buchanan, Snider, Clancy ve McBeath, mediyal PF'nin gevşetilmesinin endoskopi kontrolünde yapılmasını önermektedirler. ${ }^{[19,20]}$

\section{KOMPLIKASYONLAR}

Uygun şekilde tedavi edilmemiş PF rüptürleri, özellikle yüksek beklentisi olan atletlerde ciddi sorunlar yaratabilir. Bunlar; ayak lateral kolonunda kronik ağrı, hipertrofik skar, ilerleyici pes planus ile küboidde ve metatarslarda gelişen stres kırıkları olarak sıralanabilir. ${ }^{[6]}$ Dolayısıyla, konu ile ilgilenen hekimlerin, yaralanmaya bağlı gelişebilecek potansiyel problemlerin farkında olmaları gerekmektedir.

\section{SONUÇ}

PF rüptürleri, daha çok sporcularda görülen, akılda tutulduğu takdirde tanısı kolay konabilen ve tedavisinin planlanmasında yaralanmanın üzerinden geçen zamanın, sporcunun performansının, profesyonel durumu ve beklentilerinin dikkate alınması gereken bir durumdur.

\section{Çıkar Çatışması}

Tüm yazarlar, bu yazının hazırlanması ve yayımlanması aşamasında herhangi bir çıkar çatışması olmadığını ve herhangi bir finansal destek almadıklarını beyan ederler.

\section{KAYNAKLAR}

1. Ahstrom JP Jr. Spontaneous rupture of the plantar fascia. Am J Sports Med 1988;16(3):306-7. Crossref

2. Hoppenfeld S, deBoer P, Buckley R, editors. Surgical Exposures in Orthopaedics: The Anatomic Approach (Ortopedik Cerrahi Girişimler: Anatomik Yaklaşım), Türkçe 4. Baskı. Çev. Editörü: Prof. Dr. Uğur Şaylı. Ankara: Güneş Kitabevi, Ôncü Basımevi; 2012.

3. McElgun TM, Cavaliere RG. Sequential bilateral rupture of the plantar fascia in a tennis player. J Am Podiatr Med Assoc 1994;84(3):137-41. Crossref

4. James SL, Bates BT, Osternig LR. Injuries to runners. Am J Sports Med 1978;6(2):40-50. Crossref

5. Rolf C, Guntner P, Ericsater J, Turan I. Plantar fascia rupture: diagnosis and treatment. J Foot Ankle Surg 1997;36(2):112-4.

6. Kim C, Cashdollar MR, Mendicino RW, Catanzariti AR, Fuge L. Incidence of plantar fascia ruptures following corticosteroid injection. Foot Ankle Spec 2010;3(6):335-7. Crossref

7. Saxena A, Fullem B. Plantar fascia ruptures in athletes. Am J Sports Med 2004;32(3):662-5. Crossref

8. Hunt KJ, Anderson RB. Heel pain in the athlete. Sports Health 2009;1(5):427-34. Crossref

9. Herrick RT, Herrick S. Rupture of the plantar fascia in a middle-aged tennis player. A case report. Am J Sports Med 1983;11(2):95. Crossref

10. Sellman JR. Plantar fascia rupture associated with corticosteroid injection. Foot Ankle Int 1994;15(7):376-81. Crossref

11. Acevedo JI, Beskin JL. Complications of plantar fascia rupture associated with corticosteroid injection. Foot Ankle Int 1998;19(2):91-7. Crossref

12. Leach $\mathrm{R}$, Jones $\mathrm{R}$, Silva $\mathrm{T}$. Rupture of the plantar fascia in athletes. J Bone Joint Surg Am 1978;60(4):537-9.

13. Karagounis $P$, Tsironi M, Prionas G, Tsiganos G, Baltopoulos P. Treatment of plantar fasciitis in recreational athletes: two different therapeutic protocols. Foot Ankle Spec 2011;4(4):226-34. Crossref 
14. Nichols AW. Complications associated with the use of corticosteroids in the treatment of athletic injuries. Clin J Sport Med 2005(5);15:370-5.

15. Petraglia F, Ramazzina I, Costantino C. Plantar fasciitis in athletes: diagnostic and treatment strategies. A systematic review. Muscles Ligaments Tendons J 2017;7(1):107-18. Crossref

16. Elias DA, Carne A, Bethapudi S, Engebretsen L, Budgett R, O'Connor P. Imaging of plantar fascia and Achilles injuries undertaken at the London 2012 Olympics. Skeletal Radiol 2013;42(12):1645-55. Crossref
17. Baxter DE, Thigpen CM. Heel pain -operative results. Foot Ankle 1984;5(1):16-25. Crossref

18. Christel P, Rigal S, Poux D, Roger B, Witvoet J. Surgical treatment of rupture of the plantar fascia. Rev Chir Orthop Reparatrice Appar Mot 1993;79(3):218-25.

19. Lester DK, Buchanan JR. Surgical treatment of plantar fasciitis. Clin Orthop Relat Res 1984;(186):202-4.

20. Snider MP, Clancy WG, McBeath AA. Plantar fascia release for chronic plantar fasciitis in runners. Am J Sports Med 1983;11(4):215-9. Crossref 